\title{
Alcoolismo:
}

\section{representações sociais elaboradas por alcoolistas em tratamento e por seus familiares}

Muriella Sisa Dantas dos Santos ${ }^{1}$

Thelma Maria Grisi Velôso ${ }^{2}$

SANTOS, M.S.D.; VELÔSO, T.M.G. Alcoholism: social representations made by alcoholics undergoing treatment and by their relatives. Interface - Comunic., Saúde, Educ., v.12, n.26, p.619-34, jul./set. 2008.

Results are presented and analyzed from a qualitative study that aimed mainly to compare the social representations regarding alcoholism made by alcoholics undergoing treatment at the Fazenda do Sol Rehabilitation Center, in Campina Grande, Paraíba, with those made by their relatives. Twelve semistructured interviews were held: six with alcoholics and six with their relatives. These interviews were subjected to thematic analysis as proposed by Bardin. The interviewees generally represented alcoholism as a disease and said that individuals needed help to recover from it. Furthermore, alcoholism was represented as something that caused losses, as the act of excessive drinking, as an inherited dependence, as a punishment or as something of demonic nature. Regarding the reasons that led them to chemical dependence, most of the interviewees attributed their dependence to family problems and friendships.

Key words: Social representations. Alcoholism. Alcoholics undergoing treatment.
Apresentam-se e analisam-se os resultados de uma pesquisa qualitativa cujo objetivo principal foi comparar as representações sociais sobre o alcoolismo elaboradas por alcoolistas em tratamento no Centro de Recuperação Fazenda do Sol, Campina Grande/PB, com as de seus familiares. Foram realizadas 12 entrevistas semi-estruturadas - seis com alcoolistas e seis com familiares - as quais foram submetidas à análise temática proposta por Bardin. De modo geral, os entrevistados representaram o alcoolismo como uma doença e, para recuperar-se dela, o indivíduo necessita de ajuda. Ressaltam-se, ainda, representações do alcoolismo como algo que provoca perdas; como o ato de beber em excesso; como uma dependência hereditária; um castigo e algo do demônio. No que se refere aos fatores que os levaram à dependência química, a maioria dos entrevistados atribui a dependência a problemas vividos na família e às amizades.

Palavras-chave: Representação social. Alcoolismo. Alcoolistas em tratamento.

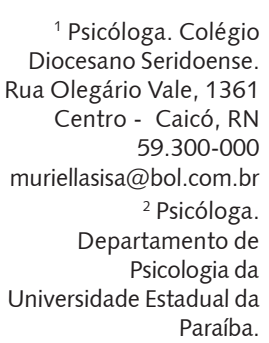




\section{Introdução}

O álcool tem sido apontado como a droga mais consumida ou, pelo menos, experimentada no Brasil. A facilidade com que essa droga é comercializada - por ser lícita - tem favorecido o seu elevado consumo, o que é apontado como umas das causas do alcoolismo, um problema que atinge milhões de brasileiros, que é considerado, por órgãos competentes, como um dos maiores problemas de saúde pública no Brasil e um dos grandes responsáveis por fatalidades em acidentes de trânsito, homicídio, suicídio e agressão (Bucher, 1992).

Pesquisas epidemiológicas demonstram que o consumo do álcool continua crescendo. As pesquisas mais abrangentes sobre o uso dessa droga foram as realizadas pelo Centro Brasileiro de Informação sobre Drogas Psicotrópicas (CEBRID). Realizaram-se quatro estudos (1987, 1989, 1993, 1997), nas mesmas dez cidades, todos com estudantes de $1^{\circ}$ e de $2^{\circ}$ graus, empregando-se a mesma metodologia. Quanto ao uso pesado de álcool, observou-se um aumento significativo na maioria das cidades estudadas, mostrando que, nos últimos anos, a juventude tende a beber com mais freqüência (Galduróz, Caetano, 2004).

Carlini et al. (2002) realizaram um levantamento sobre o uso de drogas psicotrópicas no Brasil, abrangendo as 107 maiores cidades do país. Os resultados obtidos revelam que o consumo de drogas lícitas, especialmente o álcool e o tabaco, é superior ao das drogas ilícitas: 11,2\% da população pesquisada é dependente do álcool.

Como afirma Alfaro (1993), estudos sobre o alcoolismo são relevantes, pois se fazem urgentes novos elementos para a compreensão do fenômeno, já que se trata de um problema de saúde pública com custo social. Nessa perspectiva, encontramos vários estudos que têm provocado uma reflexão sobre essa temática. O estudo realizado por Neves (2004), por exemplo, ressalta que é preciso compreender os modos moralizantes de representação do alcoolismo: seus efeitos sobre a construção das relações sociais e sua atribuição como fator dissolvente de unidades sociais fundamentais, como a família, ou perturbador do exercício de papéis básicos, como o de trabalhador e esposo.

Em consonância com esse pensamento, Mota (2004) defende que, embora o álcool, de certa forma, seja considerado, inicialmente, como um agente produtor de sociabilidade - um dos significados da bebida em nossa sociedade - ao qual se atribui um valor positivo, ele se torna, para uma parcela da população, um agente de dissociação, um fator que gera rupturas no campo das relações sociais, na família e no trabalho.

Por outro lado, as propostas mais recentes na área de saúde pública evidenciam novas expectativas com relação ao papel da família, ressaltando o seu comprometimento no processo de promoção e prevenção da saúde, haja vista a própria Lei de Reforma Psiquiátrica no Brasil (Lei 10.216/2001).

Em virtude dessas considerações, desenvolvemos, inicialmente, uma pesquisa, vinculada ao Programa Institucional de Bolsas de Iniciação Científica (PIBIC), que privilegiou a representação social de alcoolistas em tratamento sobre o alcoolismo. Naquela pesquisa, comparamos as representações sociais sobre o alcoolismo, formuladas por alcoolistas em tratamento, no Centro de Recuperação para Dependentes Químicos Fazenda do Sol, com as de alcoolistas da Clínica Psiquiátrica Dr. Maia, ambas situadas em Campina Grande/Paraíba.

Em conseqüência de estarmos estagiando no Centro de Recuperação Fazenda do Sol, o nosso interesse cresceu no sentido de ampliar a compreensão sobre o alcoolismo, razão por que optamos por desenvolver uma pesquisa escolhendo, mais uma vez, aquela instituição.

Sendo assim, realizamos uma pesquisa em 2004, cujo objetivo principal foi o de comparar as representações sociais sobre o alcoolismo, formuladas por alcoolistas em tratamento na Fazenda do Sol, com as de seus familiares. Os nossos objetivos específicos foram: analisar os fatores que alcoolistas e familiares apontam como responsáveis pela dependência; verificar em que medida o discurso religioso, inscrito na forma de tratamento da Fazenda do Sol, interfere na elaboração das representações dos alcoolistas sobre o alcoolismo, como também se existe alguma marca do discurso religioso nas representações dos familiares; e identificar elementos que assinalem a representação que alcoolistas e familiares elaboram sobre uma possível recuperação. Para isso, fundamentamo-nos na área da Psicologia Social, especificamente no campo de estudos da Teoria das Representações Sociais. 
Para Moscovici (1978), a representação social é um conjunto organizado de figuras (que se constituíram em imagens) e de expressões socializadas (que se constituíram em linguagem) que realçam e simbolizam as situações e os atos. A representação produz comportamentos, visto que define a natureza dos estímulos que nos rodeiam e provocam; ao mesmo tempo, determina esses comportamentos, à proporção que define o significado das respostas a serem dadas aos estímulos.

A representação social é uma modalidade de conhecimento particular, resultante de uma atividade psíquica, ligada a valores, normas e regras sociais, cuja função é a de elaborar conhecimentos, comportamentos e comunicação entre indivíduos. Ao representar, o indivíduo reproduz um objeto (que pode ou não ser socialmente valorizado). Enquanto reprodução do real, a representação não pode ser analisada apenas como um reflexo de um objeto na consciência individual ou coletiva. Ela detém um caráter ativo, uma vez que tal reprodução implica um remanejamento das estruturas, uma reconstrução de dados, uma remodelação dos elementos. O indivíduo, sobretudo, cria; repensa o objeto, reexperimenta-o e o refaz. "Aliás, o dado externo jamais é algo acabado e unívoco; ele deixa muita liberdade de jogo à atividade mental que se empenha em apreendê-lo" (Moscovici, 1978, p.26).

Assim, entendemos Representação Social como sendo uma forma de conhecimento que é elaborado cotidianamente pelo indivíduo e que tem, ao mesmo tempo, origem e conseqüência na produção de comportamentos e na comunicação entre indivíduos.

\section{Metodologia}

No que se refere ao percurso metodológico, optamos por realizar uma pesquisa qualitativa, uma vez que, segundo Minayo (1994), é um tipo de pesquisa que se aprofunda no universo dos significados, motivos, aspirações, crenças, valores e atitudes, e que, portanto, preocupa-se com um nível de realidade que não pode ser quantificado.

Para a coleta de dados, realizamos entrevistas semi-estruturadas que, segundo Cruz Neto (1994), consistem na articulação de duas modalidades de entrevistas: as estruturadas - que pressupõem perguntas previamente formuladas - e as nãoestruturadas - em que o entrevistando aborda, livremente, o tema proposto.

${ }^{3}$ A Fazenda do Sol disponibiliza tratamento apenas para alcoolistas do sexo masculino.

Foram realizadas 12 entrevistas, seis com alcoolistas do sexo masculino ${ }^{3}$ que se encontravam em tratamento, na época da pesquisa, no Centro de Recuperação para Dependentes Químicos Fazenda do Sol, e seis com seus familiares: cinco, do sexo feminino, e um, do sexo masculino.

A idade dos alcoolistas variava de 22 a 44 anos, e a dos familiares, de 18 a 63 anos. Dos seis alcoolistas entrevistados, três eram casados, e três, solteiros; destes, dois cursaram o primeiro grau completo, dois não o concluíram, um cursou o segundo grau completo, e um não havia concluído o segundo grau. O tempo de permanência na instituição variava de dois meses a dois anos e um mês. Com relação à profissão, um era pintor de automóveis, dois eram vigilantes, um era segurança, um trabalhava como motorista e um era garçom.

No grupo dos familiares, quatro eram casados, e dois, solteiros; um havia cursado o primeiro grau completo, dois não haviam concluído, dois cursaram o segundo grau completo, e um, o superior. Quanto ao grau de parentesco dos familiares, quatro eram irmãos de alcoolistas, uma era filha, e uma, mãe. No que diz respeito à profissão, o grupo era formado por: uma estudante, duas 
supervisoras do lar, uma lavadeira de roupas, uma professora e um comerciário.

Quanto à origem social dos entrevistados, segundo o coordenador da instituição Fazenda do Sol, eles se disponibilizam a receber pessoas de todas as classes sociais, no entanto, os que mais procuram a instituição são os pertencentes às classes sociais baixa e média.

As entrevistas foram realizadas com base em um roteiro de questões contendo 12 perguntas, previamente elaboradas de acordo com os propósitos da pesquisa. O número de entrevistas foi determinado de acordo com o número de alcoolistas internos no momento da pesquisa, pelo critério de acessibilidade e pelo número de familiares que residiam na mesma cidade em que está localizada a instituição.

As entrevistas foram gravadas em fitas cassete, transcritas na íntegra e analisadas com base na técnica da análise de conteúdo, mais precisamente da análise temática, proposta por Bardin (1977).

No que se refere à Fazenda do Sol, segundo informações obtidas na instituição, ela foi fundada no dia 13 de agosto de 2001, por um grupo de profissionais (um juiz, três médicos, um comerciante, um advogado e empresários), todos ligados à Igreja Católica, que se reuniram e decidiram criar a instituição, que se mantém por meio de trabalhos voluntários e ajudas filantrópicas, recebendo grande apoio da Igreja Católica. Além disso, os internos que têm melhores condições financeiras pagam um salário-mínimo de entrada e meio salário por mês. Os demais contribuem com o que podem.

A terapia ocupacional desenvolvida na Fazenda do Sol consiste num preenchimento do tempo dos internos, com atividades desenvolvidas por eles próprios, tais como: fabricação de tapetes; reciclagem de espuma; artesanato com jornais; limpeza em geral; reciclagem de madeira; montagem de placas eletrônicas etc. Aos sábados, participam de um trabalho de terapia de grupo, coordenado por uma psicóloga, que é católica. Observamos que, enquanto facilitadora do grupo, essa profissional se utilizava do discurso religioso, reforçando, entre outras coisas, a idéia de que a recuperação é algo dado por Deus.

Além dessas atividades, a Igreja Católica realiza, todos os domingos, uma missa na instituição, parte essencial do tratamento. A visita dos familiares, que são convidados a participar da missa, é também aos domingos, uma vez ao mês. Vale salientar ainda que o próprio coordenador do grupo também é da Igreja Católica e acredita ter recebido o chamado divino para coordenar a Fazenda. Assim, diariamente, fazia orações com todos os internos no pátio da instituição, sobretudo antes das refeições, com a finalidade de renovar a fé na recuperação, por meio da crença em Deus. Vale também sublinhar que os Alcoólicos Anônimos (AAs) costumam realizar palestras na Fazenda do Sol.

\section{O que é o alcoolismo}

Neste artigo, apresentaremos uma parte da pesquisa - as representações sociais elaboradas pelos nossos entrevistados sobre o alcoolismo e sobre as causas que os levaram à dependência.

\section{O alcoolismo é uma doença}

A análise das representações sociais sobre o alcoolismo, elaboradas pelos seis alcoolistas em tratamento na Fazenda do Sol e por seus familiares, conduz-nos às seguintes considerações: em primeiro lugar, o alcoolismo foi representado como doença, porém essa representação, como poderemos observar a seguir, vem associada à tristeza/solidão, a algo incurável, grave ou, ainda, a uma doença que, estando o indivíduo com ela, necessita de ajuda para recuperar-se.

A representação do alcoolismo como doença assemelha-se à interpretação elaborada pelo modelo biomédico, que circunscreve a doença alcoólica no âmbito biológico e fisiológico. Nesse sentido, Campos (2005), em seu estudo acerca das representações de ex-bebedores sobre o contágio e a doença, defende que a maioria concebe o alcoolismo como uma "doença inata", enraizada no organismo do alcoólico, que constrange a vontade do indivíduo, impedindo-o de agir de modo responsável.

Assim, a representação do alcoolismo como doença nos remete aos universos reificados do saber. Moscovici (1981) apud Sá (1993) considerava, nas sociedades contemporâneas, a coexistência de duas classes distintas de universos de pensamento: os universos reificados e os universos consensuais. Nos universos reificados, circulam as ciências e o pensamento erudito em geral; nos universos consensuais, as atividades intelectuais da interação social cotidiana, ou teorias do senso comum, por meio das quais 
são produzidas as representações sociais. Nesse contexto, uma realidade social é criada apenas quando o novo ou o não familiar, que geralmente se encontra nos universos reificados, passa a ser incorporado aos universos consensuais, representando, assim, o não usual em nosso mundo usual. A fim de compreender esse fenômeno, o referido autor estabeleceu o princípio da "transformação do não familiar em familiar", justificando a formação das representações sociais. Para ele, a tensão gerada pelo não familiar impede que a habituação mental domine completamente, pois o estranho intriga e perturba as pessoas, por isso é necessário transformar o estranho em familiar.

Não podemos, pois, deixar de sublinhar que, embora o discurso médico (universo reificado) influencie na representação do alcoolismo como doença, essas informações são ressignificadas pelos sujeitos a partir do contexto econômico e sociocultural no qual estão inseridos, porquanto, como afirma Arruda (2002, p.134), "O sujeito do conhecimento é um sujeito ativo e criativo, e não, uma tábula rasa que recebe passivamente o que o mundo the oferece, como se a divisória entre ele e a realidade fosse um corte bem traçado."

Como dito anteriormente, o alcoolismo é representado como uma doença que traz tristeza/solidão, como mostra a fala seguinte:

Pra mim, o alcoolismo em si é uma doença. Mas beber pra mim antes era um refúgio, era um desabafo, era uma... fugir da tristeza, né? Fugir da solidão. Era isso que eu pensava antes de adoecer. Agora o alcoolismo é totalmente o inverso do que eu pensava, é onde tá a solidão, de onde vem a tristeza, onde vem a falta de confiança, onde vem tudo aquilo que a pessoa não quer ser, não quer passar na vida. No princípio você diz que vai tomar uma pra alegrar, tomar uma pra passar o frio, tudo é em vão. A bebida não é nada mais do que a morte. (VAL, alcoo $)^{4}$

Observa-se que esse entrevistado, remetendo-se à sua experiência pessoal, ao mesmo tempo em que representa o alcoolismo como doença, deixa explícito que sua visão mudou após "adoecer". Antes, beber, para ele, era uma fuga de situações que traziam tristeza. Hoje, é completamente o oposto, o alcoolismo o faz se deparar com sentimentos de solidão, tristeza e desvalorização de si próprio - "a bebida é a morte". Convém destacar que nenhum familiar associou o alcoolismo à tristeza/ solidão.

Podemos constatar também, por intermédio das entrevistas, que o alcoolismo é representado como uma doença incurável, como assinala o discurso:

O alcoolismo é uma doença, é uma doença que ela é incurável, mas ela tem um tratamento, e você querendo, você morre sóbrio sem ingerir nenhuma gota de álcool, aí só depende de si mesmo. Você tem a ajuda, porque os Alcoólicos Anônimos mostra o caminho certo a gente, a gente segue se quiser. A gente nunca é obrigado a fazer aquilo que não quer, mas lá ele ensina a gente, digamos assim, a obrigar a fazer a coisa certa [...] eu me conscientizei que eu sou doente alcoólatra, eu não posso ingerir a primeira dose porque tudo começa pela primeira. (SEB, irmão)

Verificamos que, embora veja o alcoolismo como uma doença incurável, esse familiar também consegue encontrar para ela uma possível solução, que seria evitar o primeiro gole de álcool, o que denota uma referência ao discurso dos AAs. ${ }^{5}$ Durante 
as entrevistas, ficamos sabendo que o entrevistado, SEB, participou desse grupo e hoje se considera um ex-dependente do álcool. Cumpre assinalar que alguns internos também já participaram desse grupo.

O alcoolismo é representado, ainda, como uma doença grave: "Pra mim, eu digo hoje, com toda a afirmação, o alcoolismo é uma doença, uma doença e grave, né? Que chega até a matar, se a pessoa não procurar ajuda em tempo, né? É... o meu jeito que eu sei do alcoolismo é esse" (RUB, alcoo).

Podemos observar que RUB representa o alcoolismo como uma doença grave, que leva à morte se a pessoa não procurar ajuda. Da mesma forma, uma familiar, quando questionada sobre o que é um alcoolista, também representa o alcoolismo como uma doença que, uma vez estando o indivíduo com ela, precisa de muita ajuda para recuperar-se:

O alcoólatra é uma pessoa doente, né? Que precisa de muita ajuda. No meu ponto de vista, uma pessoa que tá dependente assim de qualquer vício, né só o álcool não, é uma pessoa que tá precisando de ajuda, é uma pessoa doente, é uma doença, com certeza, pra mim é mais do que uma doença uma pessoa que tem qualquer tipo de vício [...]. (JOA, irmã)

Dados semelhantes foram encontrados em estudo realizado por Campos (2004) acerca das representações sobre o alcoolismo dos integrantes do grupo AAs, situado num bairro da periferia de São Paulo. O referido autor afirma que alguns entrevistados representam o alcoolismo como uma doença, sendo necessário àquele que está acometido por ela procurar ajuda. Os membros dos AAs reconhecem-se como "doentes alcoólicos em recuperação", em oposição à imagem de "bêbado e cachaceiro" dos tempos do alcoolismo ativo, adquirindo assim um status de doente, com uma positividade não encontrada na condição do "bêbado" e do "cachaceiro".

Para o referido autor, os AAs defendem uma teoria segundo a qual o indivíduo não é responsável pela aquisição do alcoolismo, visto que esse mal é considerado inato, inerente ao organismo do alcoólico, e pelo qual ele não pode ser responsabilizado.

Em um estudo posterior, Campos (2005) assinala que os AAs redefinem os termos de responsabilidade do doente alcoólico, pois, se o indivíduo não é responsável pela aquisição dessa doença, ele o é por sua recuperação.

Dessa forma, o discurso dos AAs possibilita ao alcoolista a reconstrução de sua identidade, e o álcool passa a ser entendido como elemento impuro, que deve ser evitado devido a sua relação direta com a doença alcoólica. A recuperação consiste, então, em evitar tudo o que está relacionado a essa droga. Assim, é essa representação do álcool e do alcoolismo que orienta as ações em direção à sua recuperação.

\section{O alcoolismo é uma dependência hereditária}

O alcoolismo é representado ainda como dependência hereditária:

É uma dependência hereditária acompanhada por alguns fatores. Eu acho que as pessoas bebem por causa de um problema, porque o álcool faz elas esquecerem por alguns instantes. Aos poucos, a mente vai ficando dominada e se não tiverem ajuda, não conseguem sair. (RUZ, irmã)

Em outro momento da entrevista, essa informante afirma que existem, em sua família, mais pessoas que são alcoolistas. Com isso, supomos que seja por esse motivo que ela representa o alcoolismo como uma dependência hereditária. O álcool é visto por ela também como um paliativo para o esquecimento dos problemas. Conseqüentemente, com o uso excessivo, a pessoa vai se tornando alcoólatra.

Para RUZ, o alcoolismo ainda é representado como algo que domina a mente do indivíduo, deixando-o numa posição de passividade e de sujeição ao álcool. Esse aspecto aparece também em outra entrevista, como vimos. Convém enfatizar que o alcoolismo não é representado como dependência hereditária por nenhum dos alcoolistas. 


\title{
O alcoolismo é o ato de beber em excesso
}

Ao ser questionada sobre o que entende por alcoolismo, outra entrevistada deu a seguinte resposta:
Alcoolismo eu acho que é isso que ele tá vivendo agora, você começa com uma dose pequena, dizendo: "Ah, eu vou experimentar". Meu avô mesmo antes de comer, ele tomava uma dose porque ele dizia que era pra abrir o estômago pra receber a comida. Mas não é, isso é alcoolismo, é alcoólatra, ele tá viciado já. Eu acho que alcoolismo é isso, é beber mesmo, beber sem parar, eu acho que você pensa: "Ah não, vou beber só hoje, experimentar", ou por questão social: "Vou beber numa festa, social". E sem saber que aquilo ali pode até viciar você. (ELI, filha)

Para essa informante, o vício da bebida pode começar por meio de pequenas doses, somente para experimentar, ou, ainda, "por questão social". Entretanto, são essas práticas que, segundo ela, levam a pessoa ao vício - o alcoolismo é um vício que vai sendo adquirido aos poucos. Vale sublinhar que nenhum alcoolista representou o alcoolismo como o ato de beber em excesso.

\section{O alcoolismo é uma droga}

Um dos alcoolistas entrevistados representa o alcoolismo como droga, segundo a fala:

\begin{abstract}
O alcoolismo, pra mim, do jeito que eu pensava antigamente, era um divertimento. Se a pessoa tivesse uma raiva e começasse a beber esquecia tudo. Se a pessoa pegasse uma confusão e fosse beber, a pessoa pensa que passa tudo. E eu pensei que era isso. Só que depois que eu participei de várias reuniões aqui na Fazenda do Sol sobre o alcoolismo, nesses dois meses, eu garanto que se eu sair daqui, arrumar um emprego e continuar trabalhando, todo domingo eu tô aqui. Eu já falei isso pra minha mãe. Já falei isso pra família toda. Depois que eu comecei a assistir várias reuniões aqui sobre o alcoolismo foi que eu comecei a saber que o alcoolismo é uma droga. (VAN, alcoo)
\end{abstract}

VAN afirma que "o alcoolismo é uma droga", e não, que "o álcool é uma droga", o que nos leva a supor que ele pode estar tanto se referindo ao álcool como uma droga, quanto usando o termo droga num sentido negativo, sendo, portanto, o alcoolismo uma droga porque é algo ruim, prejudicial.

Para esse entrevistado, como também para outro, como já podemos observar, o alcoolismo deixa de ser algo positivo, um divertimento, e passa a ser visto como algo muito negativo, no caso, a droga. Ao fazerem uma comparação de suas representações de alcoolismo, hoje, com as que tinham no passado, constroem uma imagem que reitera o discurso veiculado pelo tratamento recebido, afinal, são alcoolistas em tratamento num centro de recuperação.

Vale sublinhar, ainda, que um familiar, após ser perguntado sobre o que é o alcoolismo, também o representa como droga: "Uma droga, pra mim, é uma droga como qualquer outra" (VAG, irmã).

Ainda analisando o discurso de VAN, quando ele diz: "se a pessoa tivesse uma raiva e começasse a beber, esquecia tudo", podemos perceber que o álcool é representado pelo entrevistado como um alívio para os problemas, um bálsamo. Essa representação também é encontrada no estudo de Brasileiro, Brasileiro e Ramalho (1999) sobre as representações do álcool, alcoolismo e alcoolista, de funcionários de uma instituição pública. Segundo os referidos autores, aqueles que apresentam atitudes valorativas em relação ao álcool é porque o viam como paliativo para esquecer os problemas.

Em uma pesquisa com adolescentes pernambucanos, Quintela et al. (2004) apud Castanha, Araújo (2006) também encontraram dados sobre o uso do álcool associado à questão do prazer, e observam que o principal motivo para que eles o ingerissem pela primeira vez eram as sensações prazerosas.

\section{O alcoolismo é algo que provoca perdas}

Com relação às perdas sofridas, o alcoolismo é concebido como algo que afeta os neurônios, conforme afirma a seqüência discursiva que segue: 
O alcoolismo é um dos fatores que tá atingindo muita gente, e chegou a me atingir porque hoje eu tenho um pouco de problema de decorar as coisas em mente, né? [...] Me tirou alguns neurônios, eu acho que hoje eu tenho dificuldade em decorar as coisas, e paciência em estudar algo, né? [...] Então, o fator que ela [a bebida] causa é a destruição de alguns dons que Deus nos dá e não tem como recuperar, né? (GEF, alcoo)

Essa seqüência discursiva ressalta uma perda cognitiva sofrida devido ao alcoolismo, o que nos remete à representação do alcoolismo como doença. O alcoolismo destrói, segundo o entrevistado, "os dons que Deus nos dá".

Nesse sentido, uma familiar representa o alcoolismo como destruição: "Pra mim, o alcoolismo... eu não sei não, viu? O que eu tenho a dizer sobre o alcoolismo é uma destruição. A pessoa que tá dependente do álcool é uma pessoa que tá dominada, destrói a família, acaba o emprego, casamento, se for casado, se destrói também" (JOA, irmã).

De acordo com essa entrevistada, o alcoolismo acarreta problemas na família, como, também, no casamento e no emprego. No decorrer da entrevista, ela afirmou que todas essas perdas foram vividas por seu irmão.

É importante destacar que as repercussões do álcool na vida familiar aparecem também nas representações de Agentes Comunitários de Saúde (AC's), estudados por Castanha e Araújo (2006), no município de Ipojuca, Pernambuco. Campos (2004) afirma que as representações de membros dos AAs também se remetem às perdas sofridas na família, no trabalho e nas amizades. Para o autor, é a partir da tomada de consciência das perdas acumuladas durante o tempo de contato com a bebida alcoólica que os alcoolistas se dão conta de que estão "dominados pelo álcool" e que precisam de ajuda para se recuperar, o que os leva a buscarem os AAs.

O referido autor assinala que o alcoolismo, embora seja considerado um mal individual, ao mesmo tempo em que atinge o dependente também afeta sua família e o local de trabalho, deteriorando os vínculos sociais e os afetos. Caracteriza-se, portanto, como "uma doença da família". Nesse sentido, Fainzang (2007), em seu estudo sobre a Associação Francesa de Ex-bebedores Vie Libre, toma por base os discursos recolhidos junto aos cônjuges dos antigos alcoólicos, membros do movimento, para delimitar os elementos constitutivos da idéia do alcoolismo como doença contagiosa, e identificar as suas dimensões em contraposição à definição médica de doença contagiosa. A autora expõe que os cônjuges dos bebedores atribuem a si mesmos um status de doentes por contágio, apesar de saberem que essa doença não é contagiosa em termos médicos.

Assim, a referida autora defende que o alcoolismo é uma doença igualmente assumida fisiologicamente pelos próximos, já que algumas de suas marcas podem ser também lidas no corpo dos outros, como, por exemplo, alguns sintomas relatados pelos cônjuges: depressão nervosa, dificuldades para dormir e raciocinar, dores no estômago, problemas de memória, dentes danificados, falta de apetite.

Dessa forma, o "contágio" provocado pelo alcoolismo pressupõe não apenas uma proximidade física, mas também social. A autora defende que,

Se as condições de possibilidade do contágio comportam o compartilhamento de um mesmo espaço físico, do mesmo ar, elas implicam necessariamente, além disso, o compartilhamento de um mesmo espaço social. A transmissão da doença de um corpo a outro não se faz ao acaso, por simples proximidade corporal. É necessária uma proximidade social, sendo que a do cônjuge, neste aspecto, é exemplar, visto que ele partilha com o bebedor não apenas o mesmo ar, o mesmo espaço doméstico, poluído pelo hálito do alcoólico, como também o mesmo destino, podendo o espaço doméstico ser superposto ao vínculo matrimonial ou àquele criado pela vida em comum. (Fainzang, 2007, p. 92)

No que diz respeito às conseqüências que o alcoolismo trazem para a família, um dos entrevistados afirma: 
Pra mim, eu acho que seja o fim da carreira do que se entrega à cachaça, porque ela traz muita desgraça. Eu digo, primeiramente por mim, porque eu perdi o amor da minha família, graças a Deus, graças a Deus, tô recuperando, dos meus dois filhos, perdi minha mulher, em vez de eu ter pensado, né? [...] E aí sempre me acabando, perdendo o que eu tinha que era o amor das minhas filhas, da minha família. (AG, alcoo)

Essa seqüência discursiva reforça a idéia de que o alcoolismo destrói não só a própria pessoa - o alcoolista - mas também a relação familiar. Ressaltam-se, assim, as rupturas que são geradas na família.

O alcoolismo é representado, também, como uma derrota: "O alcoolismo, eu acho que seja uma coisa muito... uma derrota na vida de uma pessoa que se dá nesse tipo de... né? Nesse tipo de droga. Olha, pra mim, fumou, bebeu, teve vício, nenhum presta, todos é a derrota, a infelicidade de qualquer um que entrar nesse negócio" (MIR, mãe).

Para essa familiar, o alcoolismo é visto como algo que leva uma pessoa à infelicidade, reiterando sua representação como uma perda, uma derrota e como uma droga, algo extremamente negativo.

\section{O alcoolismo é um castigo}

O alcoolismo é representado ainda como castigo:

Primeiramente Deus, depois a Fazenda do Sol. Porque eu nunca pensava em passar dois meses do jeito que eu vinha, três meses sem beber. Passava três, quatro dias. Quando chegava o final de semana, parece que era um castigo mesmo. [...] Tá vendo aí o que eu fiz da minha vida? Mas se Deus quiser, Deus vai melhorar não só a minha vida como a de todos que tão aqui na Fazenda do Sol. (VAN, alcoo)

No discurso religioso, o castigo significa algo que vem para punir uma pessoa de algum mal que ela cometeu. Dessa forma, o alcoolismo é representado pelo entrevistado como uma punição de que a pessoa tenta se livrar e não consegue. A recuperação, nesse discurso, não é conseguida por méritos próprios, mas sim, por uma dádiva de Deus que, dentro do discurso religioso, é visto como aquele que só faz o bem e que tem o poder de mudar a vida. Portanto, tendo fé n'Ele, o entrevistado acredita em sua recuperação.

É importante ressaltar, conforme já mencionado, que faziam parte do tratamento dos internos, dentre outras atividades, as missas proferidas pela Igreja Católica, das quais a família também participava. Além disso, a psicóloga que ali desenvolvia um trabalho de terapia de grupo era também católica e usava o discurso religioso nas reuniões com os internos, reforçando a idéia da recuperação como um dom oferecido por Deus.

$\mathrm{Na}$ Fazenda do Sol, o próprio coordenador do grupo ("líder espiritual") era um ex-dependente do álcool, que acreditava ter recebido a missão divina de trabalhar com os alcoolistas para ajudá-los em sua recuperação: "Olha, eu tô aqui porque foi uma longa história, eu acho que foi, foi coisa de Deus... Cheguei aqui como um enviado, né? Que recebi o chamado e vim, e esse chamado eu tô respondendo até hoje. Cada vez ele é maior" (ED, coordenador da Fazenda do Sol).

Mediante o exposto, observamos que as representações trazem as marcas do discurso religioso veiculado na instituição. Nesse sentido, um alcoolista, ao representar o alcoolismo como uma doença mental, sugere, em seguida, que ele é coisa do diabo:

O alcoólatra é aquela pessoa que ver o álcool em primeiro lugar, troca até Deus, troca até uma oração. [...] Aí é uma doença mental, você não tem controle não. Você tenta se livrar dela, muito difícil, parece que é coisa do diabo, que você quer se afastar, aí mais aparece, pode faltar comida, cachaça não, sempre aparece alguém pra te oferecer. ( $V A L$, alcoo)

A Teoria das Representações Sociais define dois processos de formação das representações: a ancoragem e a objetivação. Jodelet (1988), principal colaboradora e continuadora do trabalho de 
Moscovici, conceitua o processo de objetivação como sendo o modo por meio do qual se faz concreto o abstrato, representado pela palavra que o materializa (intercâmbio entre percepção e conceito).

O segundo processo, o de ancoragem, caracteriza-se pela integração cognitiva do objeto representado dentro do sistema de pensamento preexistente e das transformações derivadas desse sistema. Em outras palavras, ancorar significa incorporar o estranho ao familiar e, assim, tornar o objeto da representação conhecido do sujeito. Constitui-se em relação dialética com a objetivação, resultando na integração da novidade no sistema representativo, na interpretação da realidade e na orientação das condutas e relações sociais, expressando-as e contribuindo para sua constituição.

Observamos, então, que o entrevistado incorpora o conceito de alcoolismo ao pensamento social existente sobre doença mental e sobre o demônio. Interessante perceber como o discurso sugere que a doença mental tanto é algo incontrolável quanto é coisa do diabo. Nesse sentido, adverte-nos Lima Júnior (2003, p.46):

De acordo com Foucault (1975), o louco era considerado, até o advento de uma medicina positiva, como um possuído. E todas as histórias da Psiquiatria, até então, quiseram apontar, no louco da Idade Média e do Renascimento, um doente ignorado, preso no interior da rigorosa rede de significações religiosas e mágicas. Assim, teria sido necessário esperar a objetividade de um olhar médico sereno e, finalmente, científico para descobrir a deterioração da natureza lá onde se decifravam apenas perversões sobrenaturais.

Por outro lado, é importante sublinhar que, no discurso religioso, o diabo é visto como um tentador. $\mathrm{Na}$ seguinte passagem bíblica, vemos que Jesus, aquele que, segundo os preceitos religiosos, é representado como bom, foi tentado por ele: "A seguir, foi Jesus levado pelo espírito ao deserto, para ser tentado pelo diabo" (MATEUS, 4-1) (Bíblia Sagrada, 1993, p.634).

Para o entrevistado VAL, o alcoolismo é visto como uma tentação da qual ele quer se livrar, mas isso é muito difícil. O que leva a supor que, para se livrar do alcoolismo, o alcoolista carece da ajuda de Deus.

Mariz (1994) apud Campos (2005), em seu estudo sobre os pentecostais, assinala também que, para eles, o alcoolismo não é entendido propriamente como uma doença, mas identificado tanto às causas sociais como à influência do elemento sobrenatural, expresso pelo "inimigo oculto, o espírito maligno o demônio".

Fainzang (2007) sublinha que a ligação entre religião e grupo de bebedores é antiga. Para a autora, a religiosidade demonstrada por certos grupos é percebida por muitos observadores como uma necessidade para compensar a supressão do elemento alcoólico, passando-se assim de uma dependência a outra. Ao analisar os trabalhos dos AAs, a autora defende que os sujeitos se entregam, de fato, a um novo mestre: Deus.

Em relação a esse aspecto, Campos (2005, p.77) afirma:

O alcoólico anônimo deve ter um orientador ao qual deverá se entregar da mesma forma que se entregava ao álcool. Deus vem substituir sua antiga referência, o álcool. É esse novo "senhor" que passará a organizar a sua vida, fazendo perdurar a relação de dependência na qual o alcoólico está inscrito. (grifo do autor)

A marca do discurso religioso nas representações dos nossos entrevistados nos leva também a refletir sobre a seguinte consideração: as representações sociais refletem o contexto em que elas estão sendo veiculadas. Nesse sentido, Spink (1993, p.93) assevera:

Sendo uma forma de conhecimento, é inevitável que o estudo das Representações Sociais esteja fortemente ancorado à esfera cognitiva. Mas, o conhecimento, nessa perspectiva, jamais poderia ser entendido apenas no nível individual. Sendo produto social, o conhecimento tem de ser remetido às condições sociais que o engendraram. Ou seja, só pode ser analisado tendo como contraponto o contexto social em que emerge, circula e se transforma. 
Não podemos perder de vista também que a destinatária do discurso - no caso, a entrevistadora - era estagiária da instituição. Portanto, representava-a, de certo modo. Talvez o discurso tenha sido construído com base nas expectativas religiosas, que os entrevistados acreditam ser as da instituição e aquelas expectativas que a agradam. Também não desconsideramos que o próprio fato de escolherem um tratamento com base na religião já denota uma opção religiosa. Vale ainda ressaltar que nenhum familiar representou o alcoolismo como doença mental ou como coisa do diabo.

\section{O que os levou ao alcoolismo?}

De acordo com os estudiosos, os fatores que podem levar ao alcoolismo são variados, podendo ser de ordem biológica, psicológica, social ou, ainda, ter a contribuição de todos esses fatores. Para os entrevistados - tanto os familiares quanto os alcoolistas - os problemas vividos na família e as amizades foram os motivos principais. Entretanto, há aqueles que citam apenas as amizades, outros que se referem a problemas familiares, um que cita os problemas familiares e as amizades e, ainda, aqueles que mencionam o desemprego e as amizades como os fatores que os levaram ao alcoolismo.

É importante assinalar que a maioria dos entrevistados não se baseia no modelo biomédico, ou seja, não atribui as causas do alcoolismo ao modelo biológico e fisiológico, mas formula as causas de sua dependência ligadas a um contexto sociocultural específico.

Assim, um dos alcoolistas entrevistados acredita que o que o levou ao alcoolismo foram as amizades, conforme expressa este seu discurso: "Eu acho que foi muito pela amizade. Festinha. 'Vamos ali numa festinha e tal'" (VAN, alcoo).

É possível constatar que, segundo VAN, as amizades o influenciaram para sair, ir às festas, e assim, começar a beber até o ponto de tornar-se um alcoolista. Já para seu familiar, os fatores responsáveis por levá-lo ao alcoolismo teriam sido o desemprego e as amizades, conforme veremos mais adiante.

No momento, vale ainda ressaltar que um familiar também menciona as amizades como sendo o fator responsável por levar seu filho ao alcoolismo:

Quem levou mais ele ao alcoolismo, esses cabras já tão tudo debaixo do chão, não existem mais. Foi as amizades.[...] Meu rapaz mais velho não me dá trabalho, e esse só me deu porque se envolveu com essas mau amizades, porque se não tivesse se envolvido, ele era igual ao rapaz mais velho, não tinha entrado no álcool. (MIR, mãe)

Observa-se que, para essa informante, seu filho jamais teria entrado no alcoolismo por vontade própria. Ela afirma que, se não fosse a influência dos amigos, seu filho não teria se tornado um alcoolista. Interessante registrar que o alcoolista entrevistado, filho dessa senhora, confirma que foram as amizades que o levaram ao vício, como podemos constatar na fala:

As amizades e até meu pai também, porque ele saía pra beber e me levava junto, pra eu levar ele pra casa. Então eu comecei nessa luta aos nove anos de idade, ele me levava pra os barzinhos e a gente jogava uma sinuquinha, e depois ele vinha bêbado e eu trazendo ele, e eu ficava curioso pra saber como era, né? Então uma vez eu fui pra um aniversário que teve a bebida, [...] aí bebi muito [...] e gostei do clima que ela traz, fica mais agitado. (GEF, alcoo)

Podemos notar que não só as amizades são citadas por GEF como responsáveis por torná-lo um dependente, mas também a influência da figura paterna. Por meio do pai, ele começou a ter contato com ambientes onde existia a bebida, e isso lhe despertou curiosidade, conseqüentemente, levando-o a beber. Não podemos deixar de enfatizar que os efeitos trazidos pelo álcool - os aspectos positivos do álcool, como já explicitamos - são ressaltados como aquilo que o estimulava a beber mais.

A influência familiar aparece em outros discursos. Nesse sentido, uma entrevistada associa o alcoolismo, na vida de seu pai, ao fato de ele ter tido influência da própria família para beber: "Então eu acho que foi muito por influência de familiares, meu tio é alcoólatra, meu avô também é alcoólatra, o pai da minha mãe também foi alcoólatra, é de família isso, sabe?" (ELI, filha). 
Nessa seqüência discursiva, quando a entrevistada diz: "É de família isso", reforça o que já dissera em outro momento de sua entrevista, citado anteriormente, e que nos leva a supor que, para ela, o alcoolismo seria algo hereditário, ou seja, passado em sua família de geração em geração. Há que se ressaltar que nenhum alcoolista associa o alcoolismo apenas à influência de familiares, nem o próprio parente dessa entrevistada. Enquanto ELI atribui o fato de seu pai ter-se tornado um alcoolista a um fator externo, ele é o único de todos os entrevistados que assume a responsabilidade de ter se tornado um alcoolista por si mesmo, segundo confirma seu discurso: "Rapaz, eu acho que foi eu ter começado cedo demais, não me cuidei, aí pronto, me tornei um dependente do álcool." (EVA, alcoo).

Em outro momento do discurso do entrevistado acima, ele diz ter começado a beber aos 15 anos. Para Bucher (1992), o jovem, ao buscar a droga, pode estar procurando provar que é alguém, que tem um valor e que, além de ter uma existência própria, é independente. No estudo de Brasileiro, Brasileiro e Ramalho (1999), os autores defendem que a adolescência seria a fase na qual o sujeito experiencia a transição ao comportamento adulto, estando assim suscetível ao consumo abusivo do álcool.

Por outro lado, o que mais nos chamou a atenção no discurso de EVA foi que ele não atribui o fato de ter se tornado um alcoolista a fatores externos. Fainzang (2007) defende que há uma diferença nos discursos da causalidade alcoólica no que concerne ao alcoolismo dos homens em relação ao alcoolismo das mulheres. Nas mulheres, há uma tendência a priorizar causas psicológicas, enquanto, nos homens, há uma evocação às causas sociológicas (transmissão, pressão social, más condições de trabalho). Assim, a causa do alcoolismo masculino se situa, então, fora do bebedor (ela lhe é exógena), enquanto ela está dentro da mulher, intrinsecamente frágil (ela lhe é endógena).

A autora explica por que isso acontece ao considerar que

É preciso encontrar uma razão psicológica (depressão, fragilidade) para a mulher em quem a alcoolização é estigmatizada, mas não deve haver razão psicológica alguma (sendo necessário evocar o hábito ou a transmissão) no caso do homem, em quem a alcoolização é valorizada, na medida em que ela atesta ao mesmo tempo a sua força física - capaz de "agüentar" o álcool - e a convivência na qual está inserida. (Fainzang, 2007, p.42, grifo da autora)

O alcoolismo, nas representações dos nossos entrevistados, ainda foi associado à morte da mãe, como mostra a seguinte fala: "A perda da minha mãe, porque eu perdi ela com oito anos de idade, fui morar com o meu pai, com 14 anos saí de casa, sabe? Aí eu comecei a ficar desgostoso, sabe?" (AG, alcoo).

Para esse entrevistado, a perda da mãe trouxe um sentimento de desgosto, desencadeando outros conflitos, o que o fez tornar-se um alcoolista. Supomos que, para ele, o álcool seria representado como um bálsamo para os problemas, como encontramos em outras entrevistas. Portanto o consumo do álcool é representado como aquilo que gera esquecimento dos acontecimentos ruins da vida.

Nenhum familiar atribui o alcoolismo à perda da mãe. O irmão desse entrevistado, por exemplo, cita as amizades como sendo o fator responsável por levar seu irmão ao alcoolismo: “Amizade, né? Porque como a gente chama, no linguajar da gente, aquelas almas sebosas, né? Porque antes ele era um menino ótimo, [...] aí depois que começou a se juntar com as amizades, aí começou a beber." (SEB, irmão).

A expressão "alma sebosa" nos remete para a idéia de "alma impura". O discurso de SEB ainda sugere que, por causa dos amigos, o irmão deixa de ser uma "pessoa ótima", começa a beber. Nesse sentido, vale sublinhar que o irmão do entrevistado constrói uma imagem do alcoolista como uma pessoa irresponsável, desclassificada, “[...] um homem que não é homem, que nem o povo diz assim: 'é um cachorro'." (AG, alcoo).

Já outro entrevistado atribui à separação dos pais o fator que o levou ao alcoolismo, pois o conflito vivido por ele, por conta da separação, fê-lo tornar-se independente antes da hora, tendo de buscar amigos (de bar) para desabafar os problemas: 
Primeiro foi a controvérsia na minha família que aí atrapalhou tudo [...] Com esse problema, a gente sem tá preparado, teve que se separar, uns irmãos dos outros, pai e mãe, aí cada um teve que ficar independente, aí onde eu procurei amizades mais pra desabafar dos problemas foi com os amigos de bar, o motivo principal é mais ou menos esse aí, a separação da família. (VAL, alcoo)

Analisando essa seqüência, verificamos que ela nos sugere que o entrevistado, com a separação dos pais, deparou-se repentinamente com alguns problemas e recorreu aos amigos de bar para buscar ajuda.

É possível constatar, mais uma vez, a representação de que as amizades levam o indivíduo ao alcoolismo. A irmã desse entrevistado também assinala que seu irmão se tornou um alcoolista por causa das amizades: "Talvez tenha sido falta de trabalho e de oportunidades, acompanhado da influência de amigos. Ele saía pra beber com os amigos e daí começou a vender tudo dentro de casa pra beber, vendeu a casa e isso fez ele entrar cada vez mais no alcoolismo." (RUZ, irmã).

Verificamos, com base nesse discurso, que, apesar de a falta de trabalho ser considerada um dos aspectos responsáveis pelo alcoolismo, a influência das amizades também é ressaltada. Não raro, a família, como uma forma de se defender da possível culpa que sentiria ao se considerar responsável pelas escolhas de seus membros, transfere essa culpa para os outros, geralmente os amigos. Esse tipo de argumento protege a instituição social família de quaisquer críticas sobre o seu papel fundamental na socialização ideal esperada (Reis, 1992).

Outra familiar também se refere ao desemprego como sendo o fator que levou seu parente ao alcoolismo:

Foi o desemprego. Ele tava desempregado, e você sabe, hoje em dia é comum a pessoa tá desempregado. E tem esposa que quando o marido tá desempregado, ela tando trabalhando, em vez de ajudar, ela quer é destruir. Foi o que aconteceu na situação do casamento dele. Quando ele viu que não conseguia mesmo emprego, [...] se juntou com os colegas e começou a beber mesmo, foi o desemprego que fez ele entrar nessa depressão e nesse alcoolismo. (JOA, irmã)

Percebemos, nesse discurso, que o desemprego aparece como algo que veio desencadear problemas no casamento do irmão da entrevistada, gerando nele uma situação que acabou levando-o à depressão e ao alcoolismo. Então, o alcoolismo é desencadeado, também, por questões sociais. No entanto, é importante ressaltar que a esposa e as amizades também influenciaram o irmão da entrevistada a tornar-se um alcoolista.

As causas do alcoolismo são, portanto, remetidas, mais uma vez, aos fatores externos. Como vimos anteriormente, apenas um dos entrevistados atribui a si mesmo a responsabilidade por se tornar um alcoolista. Não estamos querendo enaltecer a responsabilização/culpabilização individual, pois sabemos dos inúmeros fatores que interferem na construção da identidade dos indivíduos. Mas não podemos perder de vista que representar esse vício como algo advindo de fatores externos, sem se responsabilizar por esse processo, exime o alcoolista da sua participação no processo de aquisição do vício de beber, reforçando a necessidade da ajuda de Deus para deixá-lo.

Assim, como adverte Campos (2004), o alcoolista, assumindo a condição de passividade frente ao alcoolismo, exime-se da culpa por ter ingressado nesse mundo e se sente impotente, necessitando, pois, de procurar ajuda. 


\section{Considerações finais}

Por meio da análise das entrevistas realizadas, constatamos que o alcoolismo foi representado como doença pela maioria dos entrevistados. No entanto, essa representação ora foi associada à tristeza/ solidão, ora a um mal incurável, ora a uma doença grave. Foi considerado ainda como: algo que provoca perdas, o ato de beber em excesso, dependência hereditária, castigo, coisa do diabo.

Se, de um lado, o alcoolismo é representado como uma "doença do indivíduo", de outro, é uma "doença da família", pois interfere diretamente nas relações familiares. Verificamos, ainda, que o discurso dos AAs, que proferem palestras na Fazenda do Sol, influencia as representações, assim como o discurso religioso veiculado pela instituição, por meio da Igreja Católica.

No que se refere aos fatores que os levaram à dependência química, constatamos que apenas um alcoolista assume total responsabilidade pela dependência. Todos os demais, alcoolistas e familiares, atribuem a dependência química a algum fator externo: a problemas vividos na família e/ou às amizades, havendo, também, quem se refira ao desemprego.

O estudo das representações sociais nos auxilia a encontrar pistas para entender como os indivíduos pensam e orientam as suas ações. Assim, temos elementos para refletir e encaminhar as nossas intervenções que, a nosso ver, devem privilegiar a autonomia, o poder de decisão, a criatividade e a participação dos atores sociais envolvidos. Então, considerar os alcoolistas como pessoas com todas as suas potencialidades, e não apenas como alcoolistas/dependentes, que necessitam de ajuda, parecenos um caminho promissor. O questionamento daquelas estratégias terapêuticas que induzem à substituição da dependência química pela "dependência divina" é outro aspecto que deve ser privilegiado nas discussões daqueles que se ocupam dessa temática e dos profissionais que estão envolvidos com as próprias políticas públicas de saúde.

\section{Referências}

ALFARO, A.A.P. Alcoolismo: os seguidores de baco. São Paulo: Mercuryo, 1993.

ARRUDA, A. Teoria das representações sociais e teorias de gênero. Cad. Pesqui., n.117, p.127-47, 2002.

BARDIN, L. Análise de conteúdo. Lisboa: Edições 70, 1977.

BÍBLIA SAGRADA. Trad. João Ferreira de Almeida. 2.ed. São Paulo: Sociedade Bíblica do Brasil, 1993.

BRASILEIRO, M.C.E.; BRASILEIRO, F.C.; RAMALHO, J.A. Álcool, alcoolismo, alcoolista e suas representações. In: FERNANDES, A.; MEDEIROS, J.L.A.; BRASILEIRO, M.C.E. (Orgs.). Olhar multifacetado na saúde. Campina Grande: EDUEP, 1999. p.75-93.

BUCHER, R. Drogas e drogadição no Brasil. Porto Alegre: Artes Médicas, 1992.

CAMPOS, E.A. As representações sobre o alcoolismo em uma associação de exbebedores: os Alcoólicos Anônimos. Cad. Saúde Pública, v.20, n.5, p.1379-87, 2004. 
CARLINI, E.A. et al. I Levantamento domiciliar sobre o uso de drogas psicotrópicas no Brasil: estudo envolvendo as 107 maiores cidades do país. São Paulo: Centro Brasileiro sobre Drogas Psicotrópicas - CEBRID, 2002.

CASTANHA, A.R.; ARAÚJO, L.F. Álcool e agentes comunitários de saúde: um estudo das representações sociais. Psico - USF, v.11, n.1, p.85-94, 2006.

CRUZ NETO, O. O trabalho de campo como descoberta e criação. In: MINAYO, M.C.S. (Org.). Pesquisa social: teoria, método e criatividade. Petrópolis: Vozes, 1994. p.51-66.

FAINZANG, S. Curar-se do álcool: antropologia de uma luta contra o alcoolismo. Niterói: Intertexto, 2007.

GALDURÓZ, J.C.F; CAETANO, R. Epidemiologia do uso de álcool no Brasil. Rev. Bras. Psiquiatr., v.26, suppl.1, p.513-6, 2004. Disponível em:<http://www.scielo.br>. Accesso em: 05 jan. 2008.

JODELET, D. Représentations sociales: phenoménes, concepts et théories. In: MOSCOVICl, S. (Org.) Psychologie sociale. Paris: PUF, 1988. p.357-78.

LIMA JÚNIOR, J. Os elos que nos cercam: representações sociais sobre a loucura elaboradas por familiares de usuários de Instituição Psiquiátrica. 2003. Trabalho Acadêmico Orientado. Departamento de Psicologia, Universidade Estadual da Paraíba, Campina Grande. 2003.

MINAYO, M.C.S. Ciência, técnica e arte: o desafio da pesquisa social. In: Pesquisa social: teoria, método e criatividade. Petrópolis: Vozes, 1994. p.9-29. MOSCOVICI, S. A representação social da psicanálise. Rio de Janeiro: Zahar, 1978.

MOTA, L.A. A dádiva da sobriedade: a ajuda mútua nos grupos de alcoólicos anônimos. São Paulo: Paulus, 2004.

NEVES, D.P. Alcoolismo: acusação ou diagnóstico? Cad. Saúde Pública, v.20, n.1, p.736, 2004.

REIS, J.R.T. Família, emoção e ideologia. In: CODO, W.; LANE, S.T.M. (Orgs.). Psicologia social: o homem em movimento. 10.ed. São Paulo: Brasiliense, 1992. p.99-124.

SÁ, C.P. Representações sociais: o conceito e o estado atual da teoria. In: SPINK, M.J. (Org.). O conhecimento no cotidiano: as representações sociais na perspectiva da psicologia social. São Paulo: Brasiliense, 1993. p.19-45.

SPINK, M.J.P. O estudo empírico das Representações Sociais. In: (Org.). 0 conhecimento no cotidiano: as representações sociais na perspectiva da psicologia social. São Paulo: Brasiliense, 1993. p.85-108. 
SANTOS, M.S.D.; VELÔSO, T.M.G. Alcoholismo: representaciones sociales elaboradas por alcoholizados en tratamiento y por sus familiares. Interface - Comunic., Saúde, Educ., v.12, n.26, p.619-34, jul./set. 2008.

Este artículo presenta y analiza los resultados de una investigación cualitativa cuyo objetivo principal fue comparar las representaciones sociales sobre el alcoholismo elaboradas por alcoholizados en tratamiento en el Centro de Recuperación Fazenda do Sol e en el estado brasileño de Paraiba con las de sus familiares. Fueron realizadas 12 entrevistas semiestructuradas seis con alcoholizados y seis con familiares. Las entrevistas fueron sometidas al análisis temático propuesto por Bardin. De modo general, los entrevistados representaron el alcoholismo como una enfermedad y, para recuperarse de ella, el individuo necesita ayuda. Se ponen de relieve, también, representaciones del alcoholismo como algo que provoca pérdidas; como el acto de beber en exceso; como una dependencia hereditaria; como un castigo; como algo del demonio. Respecto a los factores que los llevaron a la dependencia química, la mayoría de los entrevistados atribuyen la dependencia a problemas vividos en la família y a amistades.

Palabras clave: Representación social. Alcoholismo. Alcoholizados en tratamiento.

Recebido em 08/09/07. Aprovado em 25/04/08. 